\title{
EDITORIAL
}

\section{A European framework for effective tuberculosis control}

\author{
P.D.O. Davies
}

This edition of the Journal sees the publication of an important document in the control and elimination of tuberculosis in low-incidence countries [1]. The authors start with the well-founded World Health Organization (WHO) document for control in highprevalence countries but wisely do not attempt to adapt from it directly [2]. Instead, the paper is an original and well-thought-out strategy for managing the disease in European countries in which it is relatively uncommon, but where ample resources should be available.

The steady decline of tuberculosis in many Western European countries for a century and a half, lead to complacency and neglect of all aspects of disease control. Existing frameworks were dismantled or fell into disuse. Health professionals neglected teaching clinical and epidemiological facts about tuberculosis with the result that the new generation of doctors, nurses and allied medical workers were largely ignorant of the basic skills needed in the diagnosis and management of the disease [3].

The combined expertize of the WHO, the International Union Against Tuberculosis and Lung Disease (IUATLD) and the Royal Netherlands Tuberculosis Association (KNCV) has provided much needed help by drawing up this original policy document, summarizing the essential elements of tuberculosis control in low-incidence countries. The paper provides particularly useful definitions, including what constitutes a definite case of tuberculosis and the various treatment outcomes that are achieved, which can now be agreed across all European countries.

As is the case with the WHO policy document for high-incidence countries, this document begins by stressing the need for government commitment to providing the basic infrastructure to succeed in tuberculosis control. Past experience shows that without constant reminders, governments may well find higher priorities for their resources [4]. The need for a nationally-agreed programme is also emphasized, which will have to be integrated into existing structures. The programme will have to be planned, coordinated, supervized and evaluated by a core group of experienced professionals. Specific responsibilities covering specific areas of expertize are recommended.

Tuberculosis Research Unit, Cardiothoracic Centre, Liverpool, UK.

Correspondence: P.D.O. Davies, Tuberculosis Research Unit, Cardiothoracic Centre, Liverpool L14 3PE, UK. Fax: 441512932434. E-mail: Peter.Davies2@ccl-tr.nwest.nhs.uk
These will need to include bacteriological services and epidemiological surveillance as well as clinical services, adult and paediatric. Those with expertize in high-risk groups, such as immigrants and hostel dwellers, should be called upon for advise. In practice, each country should have a national tuberculosis committee.

By far the most high-risk group remains the individuals who have been born in high-prevalence countries, a fact which has already been well documented [5]. Even within this group, relative risk varies considerably, particularly according to country of origin and proximity in time to entry into the host country [6].

Government legislation may be required to provide a flexible framework for tuberculosis control based on national law. Compulsory notification, free access to medical care, including medication, and strict control of rifampicin supplies are at least envisaged. The thorny problem of what to do with uncooperative patients who pose a threat to public health is alluded to, but not answered. This will have to be done country by country [7].

"Education, education, education," one eminent European Statesman is quoted as saying [8]. This is as true for tuberculosis as anything else. At least two of the remarkably high number of outbreaks of tuberculosis experienced in the UK in 2001 were due to misdiagnosis of tuberculosis as asthma [9, 10]. Care needs to be taken with regard to who does the educating, as it may be that over-reliance on the pharmaceutical industry to sponsor postgraduate education may have caused part of the problem. Indeed, "Doctors don't think of tuberculosis because there isn't a (pharmaceutical) company producing goods saying 'think of TB"' [11]. Education will also need to extend beyond the medical professionals to include the lay public, so that potential patients can recognize the symptoms of tuberculosis and present early for diagnosis and treatment. The involvement of charities and other lay organizations in this role is vital [12].

One area in which high-prevalence countries can instruct low-prevalence countries is in outcome monitoring. Far too few tuberculosis services in the richer nations know their cure and default rates. Hopefully this will soon be rectified, at least in the UK [13]

Little is also known about the cost-effectiveness of screening and more operative research is therefore needed. 
The authors rightly point out that elimination of tuberculosis in Europe will not be achieved without a coordinated global approach by low-incidence countries to tuberculosis control in high-incidence countries. The richer will have to give to the poorer if everyone is to benefit. Former US President Bill Clinton's Dimbleby lecture in December 2001, gave a glimpse of how this might be achieved [14]. Unfortunately, there has been little evidence of the developed world's interest in the developing world to date. Investment by pharmaceutical companies into new drugs for tuberculosis has been pathetically small [11]. As the authors point out, tuberculosis from developing countries is now causing the disease to increase in many Western European countries. But, if driven to xenophobia by this fact, it should be remembered that the introduction of tuberculosis by immigration into Europe is, in effect, a Western European pandemic, created in the time of the industrial revolution, coming home [11]. The situation is likely to worsen before it improves.

Though robust and comprehensive in most aspects concerning tuberculosis, there are areas where the document is curiously reticent. Preventive therapy gets just a few lines and only one regimen is recommended: a full year of isoniazid alone. This contrasts with a recent document from the author's colleagues across the Atlantic Ocean, which runs to 30 pages [15]. The European document is not meant as a comprehensive view of preventive therapy, but the prevention of tuberculosis with a regimen lasting twice as long as the treatment of disease is unlikely to be practical in the service setting [16], even though it worked well in clinical trials. The 3-month regimen of isoniazid and rifampicin, though less well researched, seems eminently more practical $[17,18]$.

It is encouraging to see a paper headed by a Dutch author endorsing the use of bacille Calmette-Guérin (BCG) to prevent disease in infants. The thorny topic of whether BCG should be discontinued in low-risk groups is only given a mention. Yet, in terms of cost, most Western countries using routine BCG probably spend more on this aspect of disease control than any other. The debate about discontinuation of routine BCG perhaps deserves greater space. The argument about BCG in Western Europe is not so much about efficacy, as cost effectiveness [19].

Directly-observed therapy receives relatively little attention compared with its importance in the WHO recommendations for the developing world [2]. However, in difficult therapeutic settings in rich and urban areas of the developed world, its place is undisputed [20].

Human immunodeficiency virus (HIV)-/acquired immune deficiency syndrome (AIDS)-related tuberculosis, which are of increasing importance in Western Europe, also get scant attention. Here, the main problem in management may be the need for better communication between those managing AIDS and those managing tuberculosis [21].

Drug resistance is also mentioned only fleetingly. Yet in terms of resources needed to treat patients and control infection, it is likely to be the most expensive component of any tuberculosis service [22].
Each European country will need to scrutinize this document carefully to find out how best to apply the principles outlined. Specific guidelines may need to be drafted by each country. Previously published management guidelines will be of help [17, 23, 24].

In conclusion, education and political will are probably the most important aspects of tuberculosis control. The need for education among medical professionals, politicians and the lay public is rightly emphasized. At present, despite increasing attempts at publicity, public knowledge about the disease is still woefully lacking [25].

This is an important and powerful document, which should find its way onto the desk of the relevant Minister of State of every country in Europe with tuberculosis rates $<20$ of 100,000 . It is up to those with direct responsibility for the care of patients with tuberculosis and control of the disease, to see that it arrives there.

\section{References}

1. Broekmans JF, Migliori GB, Rieder HL, et al. European framework for tuberculosis control and elimination in countries with a low incidence. Recommendations of the World Health Organization (WHO), International Union Against Tuberculosis and Lung Disease (IUATLD) and Royal Netherlands Tuberculosis Association (KNCV) Working Group. Eur Respir J 2002; 19: 765-775.

2. World Health Organization. WHO Tuberculosis Programme framework for effective tuberculosis control. World Health Organization Document WHO/TB/ 94.1: 1-7. Geneva, World Health Organization, 1994.

3. Horne NW. Problems of tuberculosis in decline. $B M J$ 1984; 288: 1249-1251.

4. Ormerod LP for the Joint Tuberculosis Committee. Audit of TB service provision in the high incidence districts of England: 2001. Thorax 2001; 56: Suppl. iii, 58.

5. Rieder HL, Zellweger J-P, Raviglione MC, Keizer ST, Migliori GB. Tuberculosis control in Europe and international migration. Eur Respir J 1994; 7: 15451553.

6. Rose AMC, Watson JM, Graham C, et al. Tuberculosis at the end of the twentieth century in England and Wales: results of a national survey in 1998. Thorax 2001; 56: 173-179.

7. Coker RJ. From Chaos to Coercion: detention and the control of tuberculosis. London, St Martins Press, 2000.

8. Speech by Tony Blair, The prime minister launching Labour's education manifesto at the University of Southampton. www.guardian.co.uk/Archive/Article/ 0,4273,4191389,00.html. The Guardian, May 23, 2001. Date accessed: December 14, 2001.

9. Watson JM, Moss F. TB in Leicester: out of control, or just one of those things? BMJ 2001; 322: 11331134.

10. Leese J. Tuberculosis - a 19th century disease in the 21st century. Chief Medical Officers update 31. London, Department of Health, 2001.

11. Ainsworth C, Mackenzie D. Coming Home. New Scientist 2001; 171: 28-33. 
12. Davies P. TB Alert - a new tuberculosis charity. BTS News 1998; 10: 6.

13. Anon. Outcome Surveillance Tuberculosis update. London, Communicable Diseases Surveillance Centre. September 2001; 3 .

14. The struggle for the soul of the 21 st century. www.bbc.co.uk/dimbleby. Date updated: December 14, 2001; Date accessed: December 14, 2001.

15. American Thoracic Society Centers for Disease Control Prevention. Targeted Tuberculin testing and treatment of Latent Tuberculosis Infection. Am J Respir Crit Care Med 2000; 161: S221-S243.

16. O'Brien RJ. Preventive therapy. In: Davies PDO, ed. Clinical Tuberculosis. 2nd Edn. London, Chapman and Hall, 1998; pp. 397-416.

17. Hong Kong Chest Service/Tuberculosis Research CentreMadras/British Medical Research Council. A double-blind placebo-controlled clinical trial of three anti-tuberculosis chemoprophylaxis regimens in patients with silicosis in Hong Kong. Am Rev Respir Dis 1992; 145: 36-41.

18. Ormerod P, Skinner C, Moore-Gillon J, et al. Control and prevention of tuberculosis in the United Kingdom: Code of practice 2000. Joint Tuberculosis Committee of the British Thoracic Society. Thorax 2000; 55: 887-901.
19. Watson JM. BCG - mass or selective vaccination? J Hosp Infect 1995; 30: 508-513.

20. Frieden T, Fujiwara PI, Washko RM, Hamburg MA. Tuberculosis in New York city - turning the tide. N Engl J Med 1995; 333: 229-233.

21. Sudre P, Hirschel B, Toscani L, Ledergerber B, Rieder HL. Risk factors for tuberculosis among HIV-infected patients in Switzerland. Swiss HIV Cohort Study. Eur Respir J 1996; 9: 279-283.

22. White VLC, Moore-Gillon J. Resource implications of patients with multidrug resistant tuberculosis. Thorax 2000; 55: 962-963.

23. Joint Tuberculosis Committee of the British Thoracic Society. Chemotherapy and management of tuberculosis in the United Kingdom: recommendations 1998. Thorax 1998; 53: 536-548.

24. Migliori GB, Raviglione MC, Schaberg $\mathrm{T}$, et al. Tuberculosis management in Europe. Recommendations of a working group of the European Respiratory Society (ERS), the World Health organisation (WHO) and the International Union Against Tuberculosis and Lung Disease, European Region (IUATLD). Eur Respir J 1999; 14: 978-992.

25. Corless J, Myers S, Davies PDO. A world-wide internet survey of public knowledge about tuberculosis. Respir Med 2002; 96: 59-60. 